Article

\title{
Comparison Analysis and Evaluation of Urban Competitiveness in Chinese Urban Clusters
}

\section{Haixiang Guo ${ }^{1,2,3, *}$, Xiao Liu ${ }^{1}$, Yijing Li ${ }^{1}$, Deyun Wang ${ }^{1,2}$ and Xiaohong Chen ${ }^{3}$}

1 School of Economics and Management, China University of Geosciences, Wuhan 430074, China; E-Mails: liuxiao_1989@hotmail.com (X.L.); liyijing024@hotmail.com (Y.L.); m.deyun.wang@gmail.com (D.W.)

2 Research Center for Digital Business Management, China University of Geosciences, Wuhan 430074, China

3 School of Business, Central South University, Changsha 410083, China; E-Mail: csu_cxh@163.com

* Author to whom correspondence should be addressed; E-Mail: faterdumk0732@sina.com or zhukejun@cug.edu.cn; Tel.: +86-159-2738-9298; Fax: +86-27-678-832-01.

Academic Editor: Marc A. Rosen

Received: 13 January 2015 / Accepted: 8 April 2015 / Published: 15 April 2015

\begin{abstract}
With accelerating urbanization, urban competitiveness has become a worldwide academic focus. Previous studies always focused on economic factors but ignored social elements when measuring urban competitiveness. In this paper, a city was considered as a whole containing different units such as departments, individuals and economic activities, which interact with each other and affect its economic operation. Moreover, a city's development was compared to an object's movement, and the components were compared to different forces acting upon the object. With the analysis of the principle of object movement, this study has established a more scientific evaluation index system that involves 4 subsystems, 12 elements and 58 indexes. By using the TOPSIS method, the study has worked out the urban competitiveness of 141 cities from 28 Chinese urban clusters in 2009. According to the calculation results, these cities were divided into four levels: A, B, C, D. Furthermore, in order to analyze the competitiveness of cities and urban clusters, cities and urban clusters have been divided into four groups according to their distributive characteristics: the southeast, the northeast and Bohai Rim, the central region and the west. Suggestions and recommendations for each group are provided based on careful analysis.
\end{abstract}


Keywords: urban cluster; TOPSIS; urban competitiveness

\section{Introduction}

Economic globalization has become a prominent trend in the 21 th century. Since they function as the dominant power of political, economic, cultural and environmental development and are a significant symbol of modernization level, urban clusters have gradually become an important development strategy for national urbanization [1-3]. As they are basic units of the urban cluster, cities' competitiveness has drawn more and more attention from scholars. In the context of urban clusters in China, the comparative competitiveness of urban clusters has usually been evaluated through the competitiveness of cities in urban clusters. Sun compared urban competitiveness among three urban clusters in China by using a factor analysis method and cluster analysis method [4]. Different methods have been adopted to evaluate cities' competitiveness in the Pearl River Delta [5,6]. The urban competitiveness of the Yangtze River Delta has been examined by various scholars as well $[7,8]$. However, previous studies were mainly confined to one or more urban clusters in a particular region, and always focused on the big urban clusters such as the Pearl River Delta and the Yangtze River Delta, while ignoring other urban clusters. Moreover, comparative studies aiming at different urban clusters were even less common. Hence, a study on the urban competitiveness of urban clusters in China is extremely essential.

Many published theoretical and empirical studies on urban competitiveness have focused on two aspects: the concept and model of urban competitiveness and its empirical analysis. The concept of urban competitiveness was proposed on the basis of national competitiveness. Michael Porter argued that urban competitiveness means the productivity of a city, which refers to its ability to create wealth and increase income [9]. He also pointed out that the "diamond model" is not only applicable to countries but also to regions and cities. Gordon and Paul put forward that urban competitiveness enables a city to create more income and employment than any other cities within its borders [10]. Douglas Webster thought that urban competitiveness is an urban area's ability to produce more products and services and that the improvement of urban competitiveness is mainly meant to raise urban residents' living standards [11]. In addition, other scholars have also contributed to the interpretation of urban competitiveness from other perspectives [12-15].

For empirical analysis of urban competitiveness, Kresl and Singh in 1999 developed a method of measuring competitiveness that involved sorting 24 large metropolitan areas in the United States and analyzed the ranking results with regression techniques [16]. Tong evaluated the competitiveness of central cities in northwest areas of China since 1990 [17]. Jiang and Shen examined the competitiveness of 253 Chinese cities at or above the prefecture level in 2000 by using the equal weighting method [18]. Singhal et al. compared the competitiveness performance of four cities in the UK [19]. A few studies on global urban competitiveness have been undertaken by scholars and research institutions [20-22].

Although scholars have made great progress in the theoretical and empirical study of urban competitiveness, these studies generally focused on factors that promote urban development, for example, the economic side, while ignoring factors that impede urban development, such as social problems and energy problems. We argue that engine growth, such as economic growth, does not 
guarantee urban competitiveness, and urban development resistance should be considered when evaluating urban competitiveness. Other conditions being equal, it is obvious that a city with less development resistance would be more competitive. Therefore, the purpose of this paper is to design a model for evaluating urban competitiveness by adopting a perspective of object movement, a model based on fully considering the forces acting on a city, including engine growth, development resistance, city interaction and environment conditions. On the basis of that model, a scientific, external and operable index system of urban competitiveness can then be constructed, and the TOPSIS method can be used to measure the competitiveness of 141 cities in 28 Chinese urban clusters in 2009.

The whole paper has been organized into five sections. Following the first section introduction, the second section introduces a three-layer hierarchical indicator system for measuring the urban competitiveness of 141 Chinese cities. The third section focuses on data sources for this study and evaluation of urban competiveness; in this section, using the TOPSIS method, the competitiveness of 141 cities in 28 Chinese urban clusters in 2009 is evaluated. After that, the comparative analysis on these cities and urban clusters is presented in the fourth section. At the end of this paper, the fifth section draws conclusions and provides suggestions for future studies.

\section{An Evaluation Index System for Urban Competitiveness}

\subsection{Urban Competitiveness Model}

As basic units of an urban cluster, component cities' competitiveness functions as an important indicator of the overall competitiveness of an urban cluster, and urban competitiveness manifests itself in many respects, such as economy, society, education and environment. Therefore, the question of how to build a scientific and external urban competitiveness model has attracted both domestic and international scholars. Up to now, quite a few models for evaluating urban competitiveness have been designed by previous researchers. There are some typical western models, such as the international competition evaluation system of countries' competitiveness established by the World Economic Forum and the Swiss International Management and Development Institute, the diamond model proposed by Michael Porter [23], and the urban competitiveness model designed by Rondinelli [24]. By contrast, a typical model in China, proposed by $\mathrm{Ni}$ in the Chinese Academy of Social Sciences, is the urban competitiveness model; another is the urban value chain model designed by the Beijing International City Development Research Institute [25,26].

Most of these models have been established on the basis of the theory of competitive advantages. However, previous studies mainly focused on the advantage factors of driving forces, but ignored those of development resistances. In other words, having little development resistance is also a competitive advantage. If a city was considered as a whole, the comprehensive competitiveness of a city would be the overall performance of driving forces and development resistances. Basing on this view, this paper establishes an urban competitiveness model by regarding city development as object movement.

Since a city was considered a whole in this study and the involved departments, individuals and economic activities were considered components of the whole, it is obvious that the interaction between them has an impact on the city as a whole. Likewise, the development of the city as a whole was compared to the movement of an object, and the components of the whole (department, individuals, etc.) 
were compared to different forces acting upon the object. From the principle of object movement, it can be seen that the object receives not only driving and resistance forces, but also influences from external conditions and interaction with other objects. Therefore, urban competitiveness is reflected in not only its individual development but also its interaction with other cities. Based on this analysis, four dimensions - engine growth, development resistance, city interaction and environment conditionshave been chosen to measure comprehensive urban competitiveness. Engine growth is the driving forces in the development of a city, development resistance is the negative effects on urban development, city interaction reflects the ability to exchange resources nearby, and environment conditions describes quality of life; the four dimensions are further divided into 12 sub-elements (see Figure 1). A brief introduction on 12 sub-elements is given below.

Economic Strength (ES) is initially used as the primary competitive weapon, and can reflect the economic level and scale of a city. The basic indicators such as GDP growth rate and GDP are important to measure the economy's gross scale and level, and total industrial output value reflects both the degree of industrialization and urbanization. The share of the tertiary sector in GDP can also reflect the quality of urbanization.

The Role of Government ( $R G$ ) reflects how efficiently the economy of a city is regulated by the government, which can be measured by five basic indicators. Financial revenue and expenditure both reflect government regulation ability. In this study, the difference between financial revenue and expenditure has not been considered, because the difference is within a controllable range in general. Thus, the financial (or expenditure) revenue and the growth rate are positive indicators for urban competitiveness. The retail price index of commodities and housing sales price index can reflect the macro-control ability for the market, and has an influence on financial revenue and expenditure. It has a positive effect on urban competitiveness.

Resident Consumption Level (RCL) plays a critical role in both economic strength and people's material standard of living for a city, which can fuel economic growth by stimulating consumption. In this study, the average wage of staff and workers, per capita disposable income of urban residents and six other indicators can reflect the status of residents' income and consumption.

Human Resources (HR) reflect the quantity and quality of workers, which can be measured by four indicators; the second industry (or the third industry) of employment proportion can also reflect labor creation ability and economic structure.

Science and Technology Strength (S\&T) plays an important role in urban competitiveness. Because it is the final promoter of productivity in urban development, six indicators can reflect science and technology strength, including number of colleges and universities in the urban area.

Social Problems (SP) reflects the social security and commercial crimes in a city. The number of fires and traffic accidents, the number of civil cases and the number of criminal cases are used to measure social problems, and the three indicators have negative effects on urban competitiveness

Energy Problems (EP) reflect energy gaps in urban development, which can be measured by two negative indicators: the energy gap and the power gap.

Human Problems (HP) concern labor's quality and education problems. It can be measured via the illiteracy rate and unemployment rate.

Opening to the Outside World (OOW) can best reflect how open a city is, that is, how many resources a city can provide for its neighboring cities. Urban imports and exports, domestic and foreign tourism 
income per year and the number of domestic and foreign tourists per year are used to measure it. Note that urban imports and exports are both profitability indicators, not considering the influence of the trade gap.

Foreign Trade Dependency (FTD) corresponds to the opening to the outside world, and represents how many advantages from resources from neighboring cities can be used to develop the city. It can be measured by the total amount of actual investment at home and abroad, actually utilized foreign investment, and urban economic concentration and diffusion ability. The urban economic concentration and diffusion reflects the economic impact on other surrounding cities.

Infrastructure (IFT) is the carriers of economic and social development. This can be measured using the area of paved roads per capita and other 6 basic indicators, which can reflect the living conditions, medical insurance and entertainment for residents in a city.

Environment level (EL) reflects the environmental pollution and management of a city. It can be measured specifically using green area per capita and five other basic indicators.

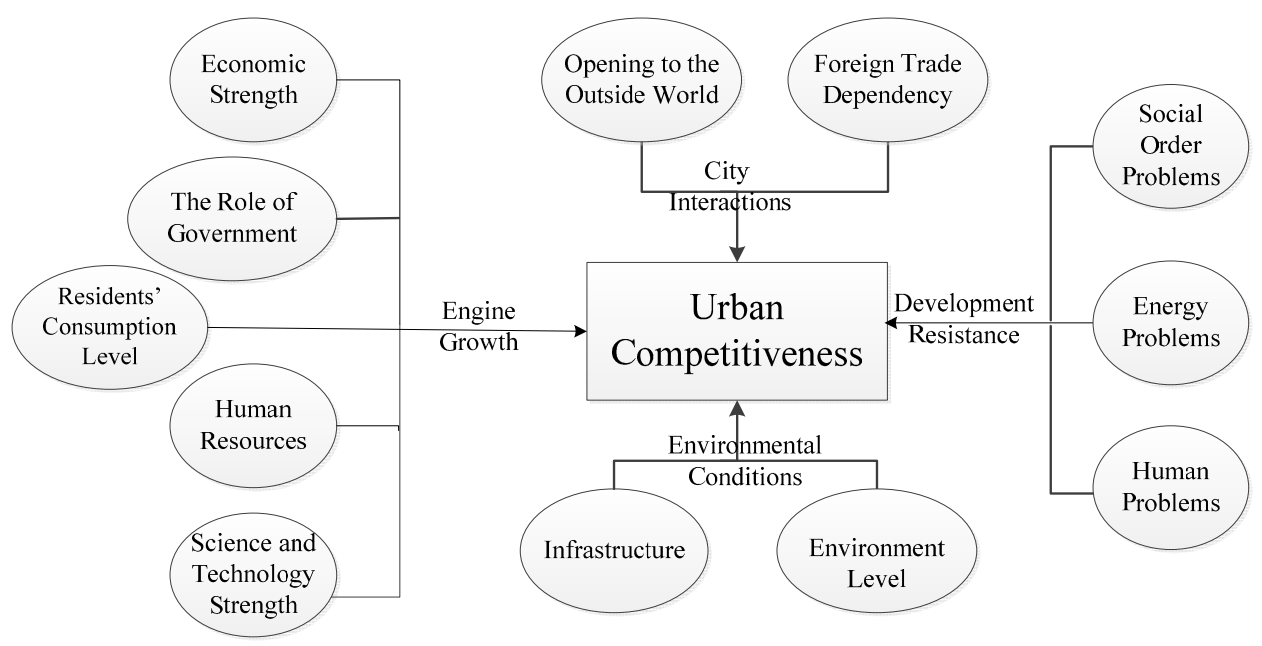

Figure 1. Urban competitiveness model.

\subsection{Construction of Urban Competitiveness Evaluation Indicator System}

Comprehensive evaluation of urban competitiveness is a complicated system to engineer and involves a series of indicators. It is not practical to consider all the factors that influence urban competitiveness. The selection of indicators is especially important and will have a direct impact on the results of the evaluation. Therefore, this paper selected some indicators that have been widely used in the previous studies, and added a few new indicators to comprehensively determine urban competiveness.

Given that comprehensiveness, science, comparability and operability are considered the four basic principles of index selection, the index system was carefully analyzed and the appearance percentages of related indicators in 138 papers written by researchers worldwide were calculated; indicators with an appearance percentage above $10 \%$ were selected as the main indicators. Meanwhile, some new indicators were involved in order to clearly reflect other factors' impact on cities' competitiveness. Firstly, the increasing demand for land area was considered a bench-marking indicator and the house sales price index was used to evaluate the government's adjustment on real estate. Secondly, the trading volume of 
the commodity exchanging market was considered an indicator under Residents' Consumption Level to reflect the local consumption level. Thirdly, college and university teachers were also taken into consideration as an indicator under Science and Technology Strength to evaluate the local education resources. Fourthly, the number of criminal and civil cases was viewed as an indicator of Social Order Problems as well as a reference to local stability. Fifthly, the energy gap fell under Energy Problems to evaluate the development level of local energy. Finally, an index system involving 4 subsystems, 12 elements and 58 indexes for the purpose of measuring urban competitiveness was established in detail and shown in Table 1.

Table 1. Index system of urban competitiveness.

\begin{tabular}{|c|c|c|c|}
\hline $\begin{array}{c}\text { Destination } \\
\text { layer }\end{array}$ & $\begin{array}{c}\text { Subsystem } \\
\text { layer }\end{array}$ & $\begin{array}{c}\text { Element } \\
\text { layer }\end{array}$ & Basic Index layer \\
\hline \multirow{8}{*}{$\mathrm{UC}$} & \multirow{5}{*}{ EG } & ES & $\begin{array}{l}\text { GDP (x1); GDP growth rate (x2); GDP per capita (x3); Share of } \\
\text { secondary sector in GDP }(\mathrm{x} 4) \text {; Share of tertiary sector in GDP } \\
(\mathrm{x} 5) \text {; total industrial output value }(\mathrm{x} 6)\end{array}$ \\
\hline & & $\mathrm{RG}$ & $\begin{array}{l}\text { Financial revenue of local government per capita (x7); Financial } \\
\text { expenditure of local government per capita (x8); Retail price } \\
\text { index of commodities (x9); Housing sales price index (x10); } \\
\text { Local financial revenue growth rate (x11); Local financial } \\
\text { expenditure growth rate (x12); The ruling government } \\
\text { satisfaction (x13) }\end{array}$ \\
\hline & & RCL & $\begin{array}{l}\text { Average wage of staff and workers (x14); Urban consumer price } \\
\text { index (x15); Per capita disposable income of urban residents } \\
\text { (x16); Per capita consumption expenditure of urban residents } \\
\text { (x17); Engel coefficient of urban households (x18); Total retail } \\
\text { sales of social consumer goods (x19); Total retail sales of social } \\
\text { consumer goods per capita (x20); Total transaction amount of } \\
\text { commodity trading market (x21) }\end{array}$ \\
\hline & & HR & $\begin{array}{l}\text { The second industry employment proportion (x22); The third } \\
\text { industry employment proportion (x23); On-the-job workers } \\
\text { proportion (x24); Number of on-the-job workers at end of the } \\
\text { year (x25) }\end{array}$ \\
\hline & & S\&T & $\begin{array}{l}\text { Number of colleges and universities (x26); Number of teachers } \\
\text { in colleges and universities (x27); Number of patent applications } \\
\text { (x28); Number of authorized patents and technology projects } \\
\text { (x29); Number of all types of professional and technical } \\
\text { personnel per } 10 \text { thousands persons (x30); Number of } \\
\text { undergraduate students per } 10 \text { thousands persons (x31) }\end{array}$ \\
\hline & \multirow{3}{*}{ DR } & SOP & $\begin{array}{l}\text { Number of fire and traffic accidents (x32); Number of civil } \\
\text { cases (x33); Number of criminal cases (x34) }\end{array}$ \\
\hline & & EP & Annual energy gap (x35); Annual power gap (x36) \\
\hline & & HP & Illiteracy rate (x37); Unemployment rate (x38) \\
\hline
\end{tabular}


Table 1. Cont.

\begin{tabular}{|c|c|c|c|}
\hline $\begin{array}{c}\text { Destination } \\
\text { layer }\end{array}$ & $\begin{array}{c}\text { Subsystem } \\
\text { layer }\end{array}$ & $\begin{array}{c}\text { Element } \\
\text { layer }\end{array}$ & Basic Index layer \\
\hline & \multirow{2}{*}{ CI } & OOW & $\begin{array}{l}\text { Unban imports (x39); Unban exports }(\mathrm{x} 40) \text {; Domestic and } \\
\text { international tourism income per year }(\mathrm{x} 41) \text {; Number of } \\
\text { domestic and foreign tourists per year }(\mathrm{x} 42)\end{array}$ \\
\hline & & FTD & $\begin{array}{l}\text { Total amount of actual domestic and international investment } \\
\text { (x43); Actually utilized domestic and international investment } \\
\text { (x44); Urban economic concentration and diffusion ability (x45) }\end{array}$ \\
\hline & \multirow{2}{*}{$\mathrm{EC}$} & IFT & $\begin{array}{l}\text { Length of paved roads per capita (x46); Electricity consumption } \\
\text { per capita (x47); Water consumption per capita (x48); Number of } \\
\text { public transportation vehicles per } 10 \text { thousand persons (x49); } \\
\text { Number of public library books per hundred persons (x50); } \\
\text { Number of doctors per } 10 \text { thousand persons (x51); Number of } \\
\text { telephones per } 10 \text { thousand persons (x52) }\end{array}$ \\
\hline & & EL & $\begin{array}{l}\text { Area of green land per capita (x53); Percentage of greenery } \\
\text { coverage in the built-up area (x54); Percentage of industrial } \\
\text { sewage discharged meeting national standard (x55); Number of } \\
\text { fine air days per year (x56); Solid waste comprehensive } \\
\text { utilization rate (x57); Output of products that comprehensively } \\
\text { utilized the "three wastes" (x58) }\end{array}$ \\
\hline
\end{tabular}

Note: In Table 1, UC = Urban Competitiveness, EG = Engine Growth, DR = Development Resistance, $\mathrm{CI}=$ City Interactions, $\mathrm{EC}=$ Environmental Conditions, $\mathrm{ES}=$ Economic Strength, $\mathrm{RG}=$ The Role of Government, RCL = Resident Consumption Level, HR = Human Resources, S\&T = Science and Technology Strength, SOP = Social Order Problems, EP = Energy Problems, HP = Human Problems, OOW = Opening to the Outside World, FTD = Foreign Trade Dependency, IFT = Infrastructure, EL = Environment Level.

\subsection{Calculation of Index Weight}

The Delphi Principle has been adopted to calculate the weight of each evaluation index. Firstly, a survey on questionnaire-designing was given out to related researchers on Provincial Development and Reform Commissions (PDRC) and some professors studying regional economy. Their feedback again contributed to the improvement of the questionnaire. Secondly, the formal questionnaires were given out and the data from those experts were collected. Thirdly, the weight of each index was calculated based on Formula (1).

$$
W_{j}=\frac{\sum_{i=0}^{n} c_{i j}}{\sum_{i=0}^{n} \sum_{j=0}^{m} c_{i j}}
$$

where $n$ represents the number of experts, $m$ represents the number of index, $w_{j}$ represents the index $j_{t h}$ weight, $c_{i j}$ represents the $j_{t h}$ score graded by $i_{t h}$ experts.

In order to obtain more scientific and authoritative opinions, through consulting experts, as mentioned above, this study firstly collected effective opinions from 36 experts from PDRCs and universities in China, of which 29 experts were from PDRCs and the other 7 from universities. According to their 
familiarity with the indexes, the following quantization table was designed (as shown in Table 2) and how these experts are authoritative in this area was further analyzed using Formula (2).

Table 2. The quantization of expert's familiarity with each index.

\begin{tabular}{cccc}
\hline Judgment Criteria & Quantization & Familiarity & Quantization \\
\hline Practical experience & 0.8 & Very familiar & 1.0 \\
Theoretical analysis & 0.6 & Familiar & 0.8 \\
Basic understanding & 0.4 & Not very familiar & 0.4 \\
Intuition & 0.2 & Minimally familiar & 0.2 \\
& & Unfamiliar & 0 \\
\hline
\end{tabular}

$$
C_{R}=\frac{C_{J}+C_{F}}{2}
$$

where $C_{R}$ represents the authority degree of experts, $C_{J}$ is the quantitative value of judgment basis, $C_{F}$ is the quantitative value of familiarity. According to the results, some experts who are less familiar with the variables were excluded. In this study, experts whose $C_{R}$ is above 0.7 are selected.

Secondly, considering that even cities from the same region may not belong to the same urban cluster, it is obvious that the opinions of PDRC experts from regions that possess more urban clusters are more important than those of experts from other regions. For instance, cities from Henan province belong to four urban clusters respectively, meaning that opinions of experts from the Henan PDRC are more important than those of other PDRC experts. According to this point, a second round of selection was conducted. Experts from the Henan PDRC and other regions' PDRCs were selected because the numbers of urban clusters in these regions are bigger than or equal to 2. Table 3 shows the number of urban clusters in each region.

Table 3. The number of urban clusters in each region.

\begin{tabular}{cccccccc}
\hline Region & Num & Region & Num & Region & Num & Region & Num \\
\hline Henan & 4 & Shanxi & 2 & Hunan & 1 & Yunnan & 1 \\
Shandong & 3 & Inner-Mongolia & 2 & Guangxi & 1 & Ningxia & 1 \\
Anhui & 3 & Jilin & 1 & Hainan & 1 & Gansu & 1 \\
Guangdong & 3 & Heilongjiang & 1 & Sichuan & 1 & Qinghai & 1 \\
Hebei & 3 & Fujian & 1 & Chongqing & 1 & Shaanxi & 1 \\
Jiangsu & 2 & Shanghai & 1 & Fujian & 1 & Guizhou & 1 \\
Zhejiang & 2 & Beijing & 1 & Tianjin & 1 & Liaoning & 1 \\
Hubei & 2 & Tibet & 0 & Xinjiang & 0 & & \\
\hline
\end{tabular}

Note: In Table 3, Num $=$ the number of urban clusters

According to the steps described above, the study finally identified 16 authoritative experts and the formal questionnaires were modified according to all the experts' advice. In the end, 16 official questionnaires were given out, of which 11 validated questionnaires were collected. Moreover, the 8 PDRC experts are from Henan, Shandong, Anhui, Guangdong, Jiangsu, Hubei, Zhejiang and Jilin and the other 3 are from universities. Finally, based on Formula (1), this study worked out index weight in each layer as shown in Appendix I. 


\section{Evaluation of City Competitiveness}

\subsection{Data Sample}

The Blue Book of Urban Competitiveness in 2007 defined 30 urban clusters in China [27]. Since the data from the Taiyuan urban cluster and Central Yunnan urban cluster is missing, this study has chosen 28 urban clusters consisted of 141 Chinese cities, nearly covering all provinces and municipalities in China (excluding Hong Kong, Macon and Taiwan). Specific information on these urban clusters and cities is provided in Appendix II.

\subsection{Data Preprocessing}

The data in this study were basically obtained from government documents, such as China City Statistical Yearbook of 2010 [28], China Statistical Yearbook on Environment of 2010 [29], China Energy Statistical Yearbook of 2010 [30], the Statistical Yearbooks of relevant provinces and cities, Statistical Bulletin for National Economic and Social development, municipal environment statistical bulletins, media and city soft power, etc. However, due to different statistical methods, data for some cities were actually inaccessible. Given the reliability and authenticity of this study, Table 4 demonstrates the processing modes that deal with the missing indices. The missing data was less than $3 \%$ of all data in this study.

Table 4. Processing mode for missing indices.

\begin{tabular}{ll}
\hline Index & Source and calculation method \\
\hline Population & $\begin{array}{l}\text { The total population at the end of the year in the } \\
\text { statistics yearbook }\end{array}$ \\
\hline $\begin{array}{l}\text { Financial revenue (expenditure) of local } \\
\text { government per capita }\end{array}$ & $\begin{array}{l}\text { Local financial revenue (expenditure)/the total } \\
\text { population in the end of the year }\end{array}$ \\
\hline KLocal financial revenue growth rate & $\begin{array}{l}\text { (Local financial revenue this year }- \text { Local financial } \\
\text { revenue last year)/Local fiscal last year } \times 100 \%\end{array}$ \\
\hline Engel coefficient of urban residents family & $\begin{array}{l}\text { Food spending amount/The amount of consumer } \\
\text { spending } \times 100 \%\end{array}$ \\
\hline Commodity trading market clinches a deal amount & $\begin{array}{l}\text { The wholesale of the total retail sales of consumer } \\
\text { goods, retail sales in the statistics yearbook }\end{array}$ \\
\hline The actual total investment of the abroad & $\begin{array}{l}\text { The amount of foreign capital of the contract in } \\
\text { statistics yearbook }\end{array}$ \\
\hline Number of fire and traffic accidents & $\begin{array}{l}\text { The number of known fire accidents } \times \text { unknown urban } \\
\text { land area/Known city land area }\end{array}$ \\
\hline Number of civil/criminal cases & $\begin{array}{l}\text { Known criminal/the number of civil cases } \times \text { unknown } \\
\text { urban population/Known urban population }\end{array}$ \\
\hline Annual energy/power gap & $\begin{array}{l}\text { Known annual energy/Power gap } \times \text { Unknown urban } \\
\text { GDP/Known urban GDP }\end{array}$ \\
\hline Illiteracy rate & \begin{tabular}{l} 
1-Primary school enrollment \\
\hline
\end{tabular} \\
\hline
\end{tabular}




\subsection{TOPSIS Method}

The TOPSIS method has been adopted for ranking the competitiveness of 141 Chinese cities in 2009. First put forward by Hwang and Yoon in 1981 [31], the TOPSIS method as one kind of MCDM (multiple criteria decision making) is a common assessment method in economic management and decision making. It defines both a positive ideal solution and a negative ideal solution and then ranks solutions on the basis of how close each alternative is to the ideal solution. If an alternative is closest to the positive ideal solution, and it is far away from negative ideal solution, then the alternative is the best solution, that is to say, the alternatives are finally ranked based on sorting the degree of closeness to ideal solution, which is calculated using Formula (3).

$$
C_{i}=\frac{D_{i}^{-}}{D_{i}^{+}+D_{i}^{-}}
$$

where $C_{i}$ represents the degree of closeness to the ideal solution, $D_{i}^{+}$represents the distance between the alternative and the positive ideal solution, and $D_{i}^{-}$represents the distance between the alternative and the negative ideal solution. Therefore, TOPSIS has some advantages over others such as stronger geometric explanation, less computation and better operability. What's more, TOPSIS is not restricted by sample or index numbers, which means that TOPSIS is suitable for large samples and major indexes in urban competitiveness. However, the disadvantage of TOPSIS is that it cannot fully reflect whether the alternative is good when the alternative is close to both the positive ideal solution and the negative ideal solution. In order to avoid this problem, our paper's analysis is based on classification according to ranking results, rather than the rankings (see Section 4).

The city competitiveness index system constructed in this study can be divided into three parts: the subsystem layer, the element layer and the basic index layer. In order to compare and analyze how these different indicators would impact urban competitiveness, the final score of urban competitiveness has to be calculated step by step. Specifically, the score of the element layer can be obtained through index weight and index data of the basic index layer. Similarly, through combining the index weight of the element layer, the score of the subsystem layer can be calculated by using the TOPSIS method. The specific steps are demonstrated in Figure 2.

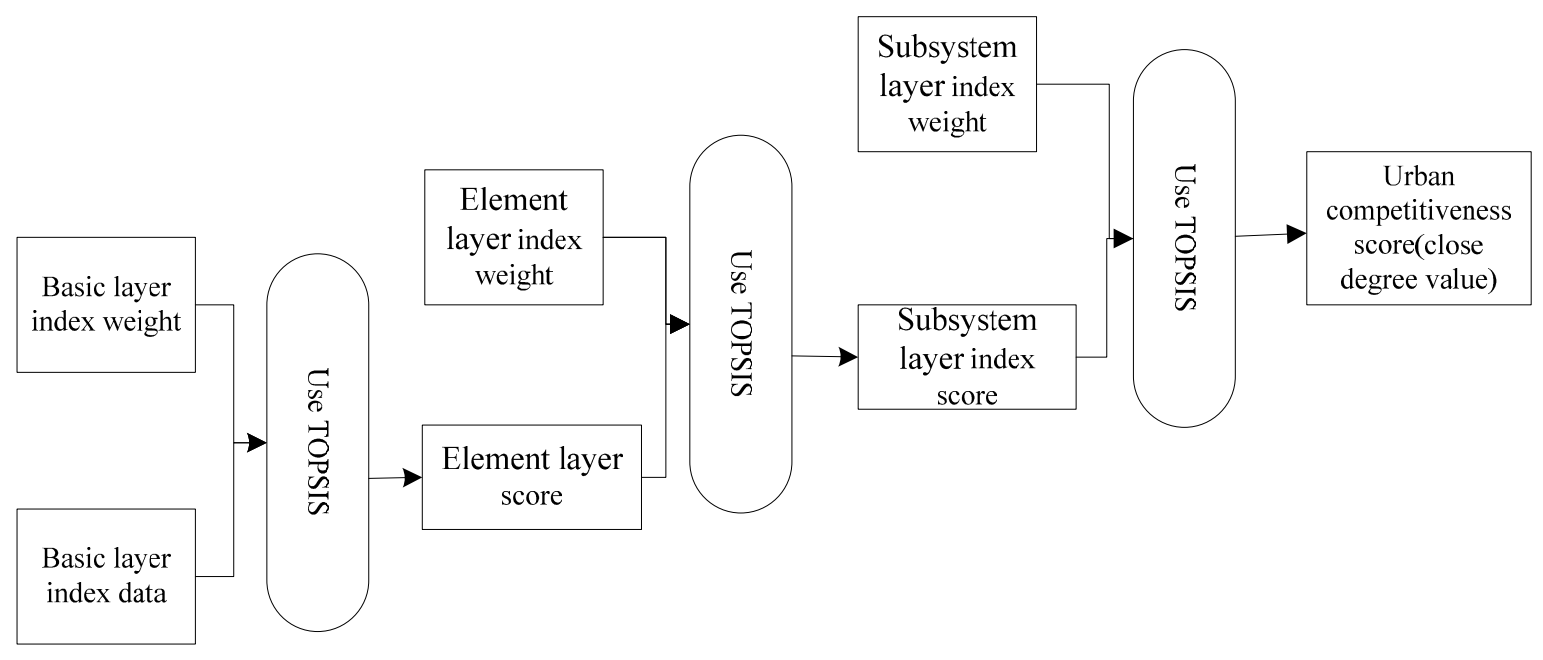

Figure 2. Calculation process of urban competitiveness. 


\subsection{The Ranking Results}

As a result, scores for the subsystem layer and urban competitiveness were finally obtained by calculating the collected indexes and their corresponding rankings, which are shown in Appendix III.

\section{Comparative Analysis of Calculation Results}

Since rankings of cities' competitiveness have shed light on the classification of urban competitiveness, four levels (A, B, C, D) were finally defined. Among all the cities, the top 35 belonged to level $\mathrm{A}$, the middle 36-70 and 71-105 belonged to level $\mathrm{B}$ and level $\mathrm{C}$ respectively, while the bottom 106-141 belonged to level D.

\subsection{Overview of Urban Competitiveness}

Based on cities' rankings and levels of competitiveness, Figure 3 shows the distributive characteristics of urban competitiveness. More than half of the A-level cities, nearly a third of the B-level cities and ten or more of the C-level cities are located in the southeast area of China, mainly because most cities obviously have enjoyed various geographic advantages and superior industrial foundations in this area. The central area has the largest A-level cities except the southeast area, but it also has the largest D-level cities, and the number is about half. According to this, urban competitiveness in the central area is very unbalanced. With the rise of the central region strategy, there is a great opportunity for cities in this area to promote their development and competiveness. The competitiveness of cities in the Bohai Rim area is mainly at the B and C levels. The overall competitiveness of this area is obviously weaker than that of the southeast, but is stronger than the central area and other regions. Cities in this area should strengthen their economic cooperation and enhance their competitiveness to increase their number of A-level cities. The remaining three regions have more than half C-level and D-level cities, especially the southeast area, which has $4 \mathrm{C}$-level and $7 \mathrm{D}$-level cities, while the total number of this area is 15 . Due to constraints in geographical location, resource conditions and policy reasons, cities in the west region are still undeveloped. It is necessary for less advanced cities to develop their economies, because economy is the foundation of both social and culture development.

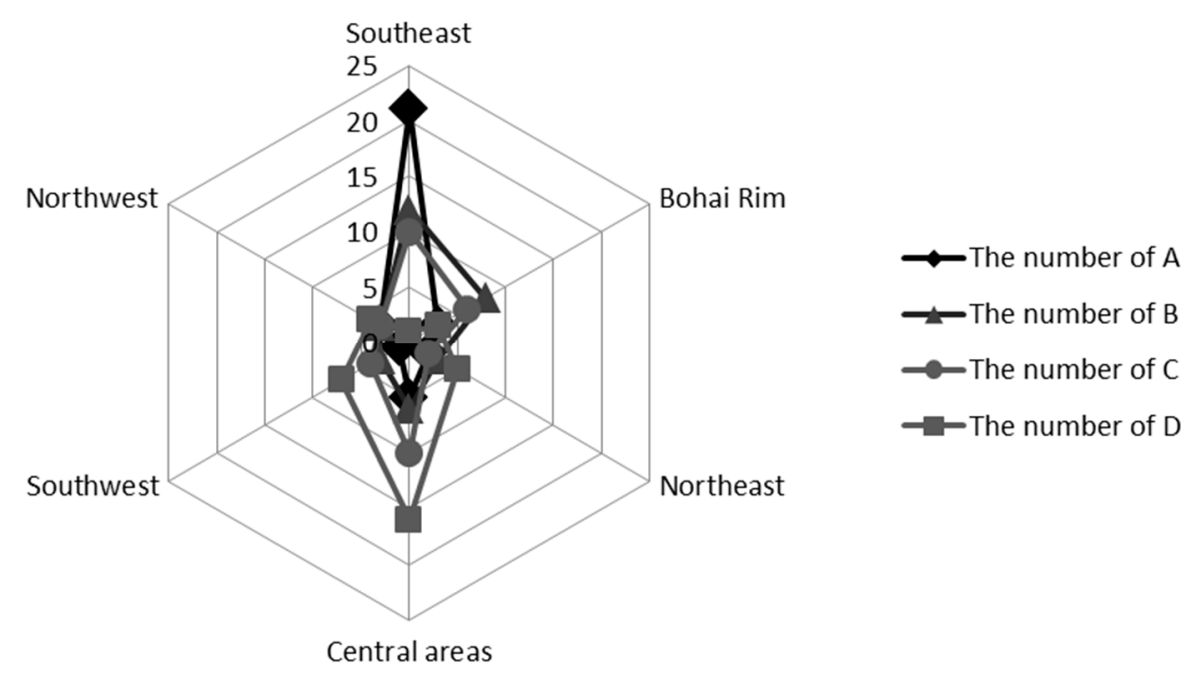

Figure 3. Area profile of each level. 


\subsection{Relationship among the Four Dimensions of Urban Competitiveness}

The urban competitiveness score is calculated by integrating engine growth, development resistance, city interaction and environment conditions. According to this, it is necessary for a city to achieve good performance in all dimensions for higher urban competitiveness. However, there are many possible trade-offs in the process of urban development, which lead to unbalanced development of different dimensions. For example, the contradiction between economic growth and environmental protection is prominent in developing countries such as China. Therefore, the relationship among four dimensions in urban competitiveness has been examined directly by correlation coefficient and scatter plot in this section. The Pearson correlation coefficients of the scores of overall competitiveness and four components were calculated. Given that cities with different levels of competitiveness may have differences in the relationships among dimensions, the analysis of relationships among dimensions is divided into five groups according to cities' levels of competitiveness.

(1) Relationships among the four dimensions of urban competitiveness of 141 cities.

The calculation result reveals that engine growth, city interaction and environment conditions are positively correlated and statistically significant at 0.05 , and the relationship between urban competitiveness and the four dimensions is also positive. However, the relationship between development resistance and other dimensions are weak, which also can be seen from the Figure 4 . Figure 4 shows that there is an obvious linear positive correlation between urban competitiveness and engine growth, with a Pearson correlation coefficient of 0.92. Similarly, the engine growth and city interaction present a positive correlation at a Pearson correlation coefficient of 0.81 . This is probably because engine growth and city interaction are closely related and interactive with each other. The relationship between engine growth and environmental conditions $(0.58)$ was closer than the correlation between city interaction and environmental conditions (0.41). Perhaps a city with better performance in EG and city interaction will help provide better environmental conditions.

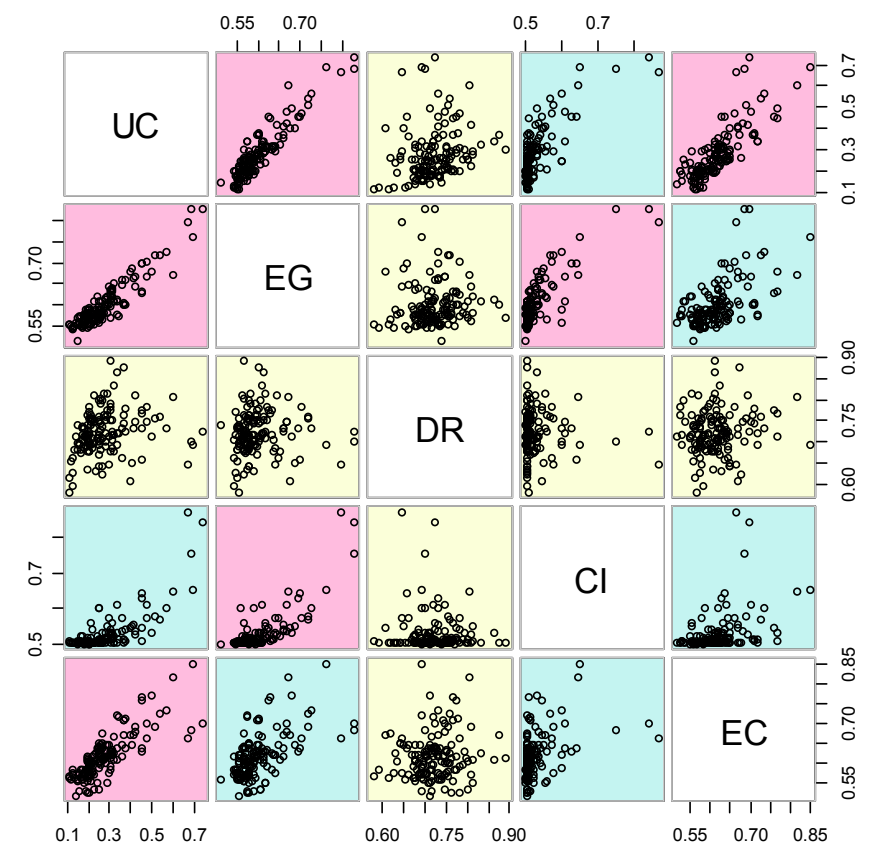

Figure 4. The scatter plot of dimensions of 141 cities. 
(2) Relationships among the four dimensions of urban competitiveness of A-level cities

Similar to the result of 141 cities, Figure 5 shows that urban competitiveness has a strong linear positive correlation with engine growth, city interaction and environmental conditions, but has a weak negative correlation with development resistance. Moreover, engine growth and city interaction both have a negative correlation with development resistance, and the correlation coefficients are respectively 0.36 and 0.34 . According to the ranking result in every dimensions of urban competitiveness, this reveals that some A-level cities may have unbalanced performance, with DR rank far behind. For instance, Guangzhou, Shenzhen, Beijing and Tianjin, the rank of development resistance are all after 90. The quick development of a city may produce some negative effects, such as social problems and energy shortages, which will increase development resistance.

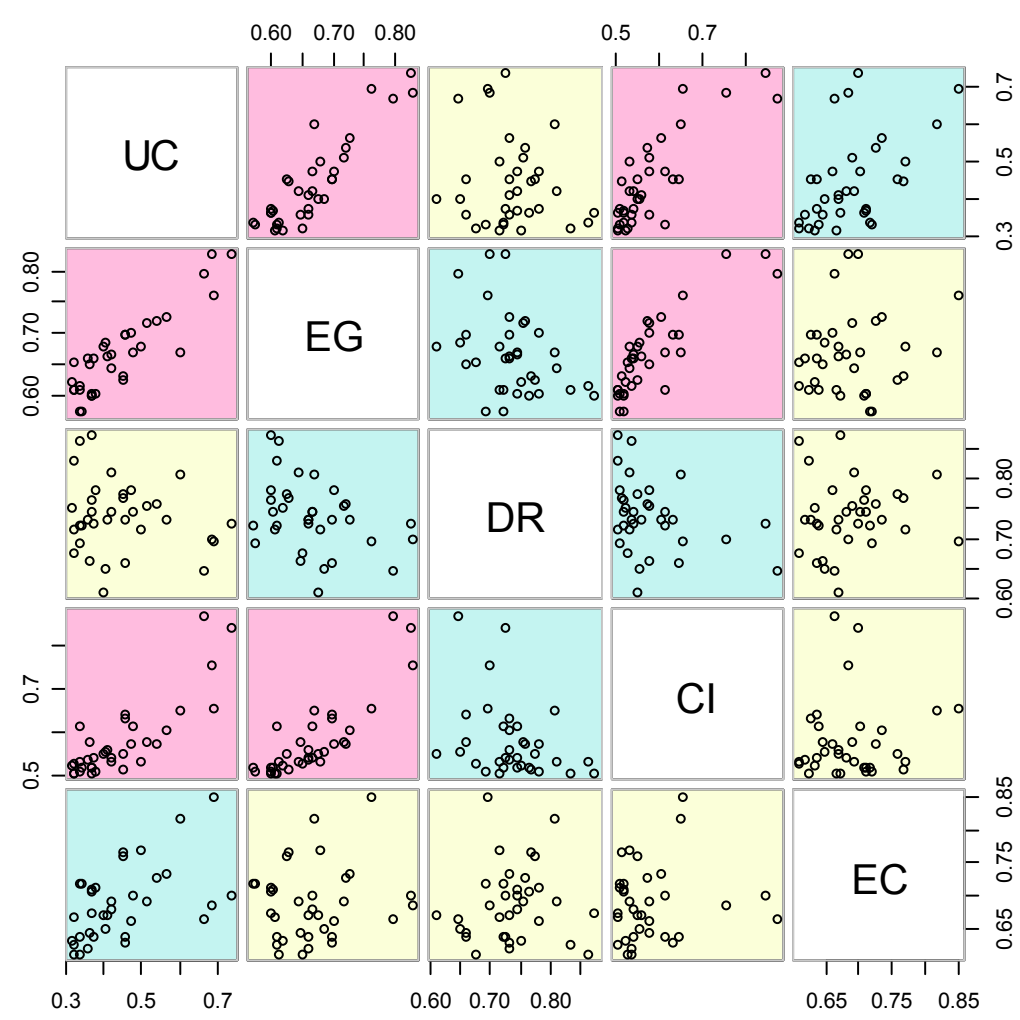

Figure 5. The scatter plot of dimensions of A-level cities.

(3) Relationships among the four dimensions of urban competitiveness of B-level cities

Compared with the two cases introduced, urban competitiveness has a weaker positive correlation with engine growth and city interaction. Figure 6 shows that the relationship between urban competitiveness and development resistance, urban competitiveness and environmental conditions are not correlated, which indicates that the urban competitiveness of B-level cities is more unbalanced in all dimensions. In addition, the negative correlation between engine growth and environmental conditions confirms that these cities may achieve rapid development at the expense of the environment. It is necessary for these cities to pay more attention to the environment while developing their economy. 


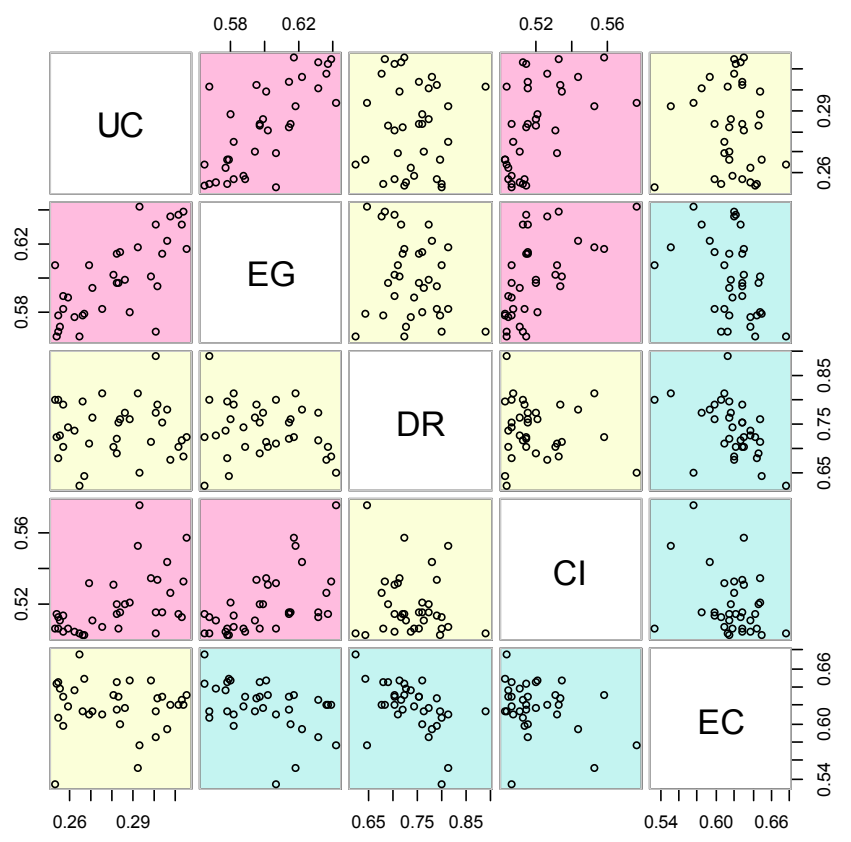

Figure 6. The scatter plot of dimensions of B-level cities.

(4) Relationships among the four dimensions of urban competitiveness of C-level cities

Figure 7 shows that urban competitiveness has a weaker positive relationship with engine growth, city interaction and environmental conditions. But according to the calculation of the correlation coefficient, only the relationship between urban competitiveness and EC is at a significant level of 0.05, with a correlation coefficient of 0.45 . That is to say, the urban competitiveness of C-level cities mainly depends on environmental conditions. Engine growth has a negative relationship with development resistance and environmental conditions, suggesting that these cities are currently in the developing period, because there are some conflicts among these dimensions which have restricted the overall development of the city.

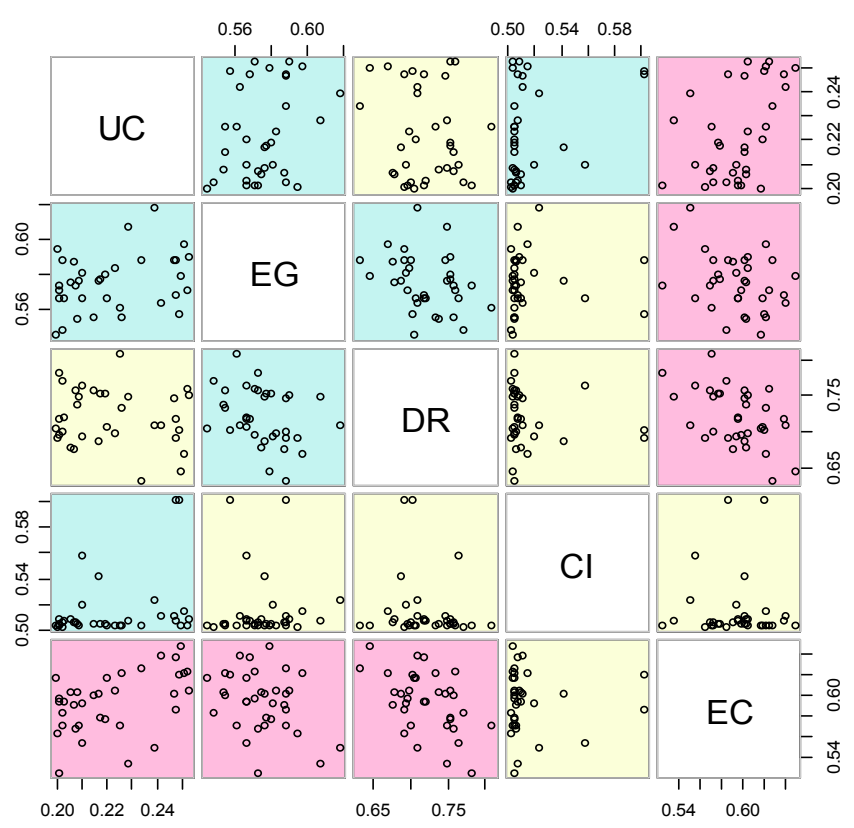

Figure 7. The scatter plot of dimensions of C-level cities. 
(5) Relationships among the four dimensions of urban competitiveness of D-level cities

Urban competitiveness has a strong positive relationship with development resistance that is different from other cities with other levels (as shown in figure 8). Meanwhile, the scores for both environmental conditions and development resistance are low, similar to the overall urban competitiveness. Due to their late start, these cities ranked far behind in all four dimensions. The different dimensions are also almost uncorrelated. Therefore, specific advantages of these cities should be identified and fully taken advantage of to achieve their balanced development in other aspects.

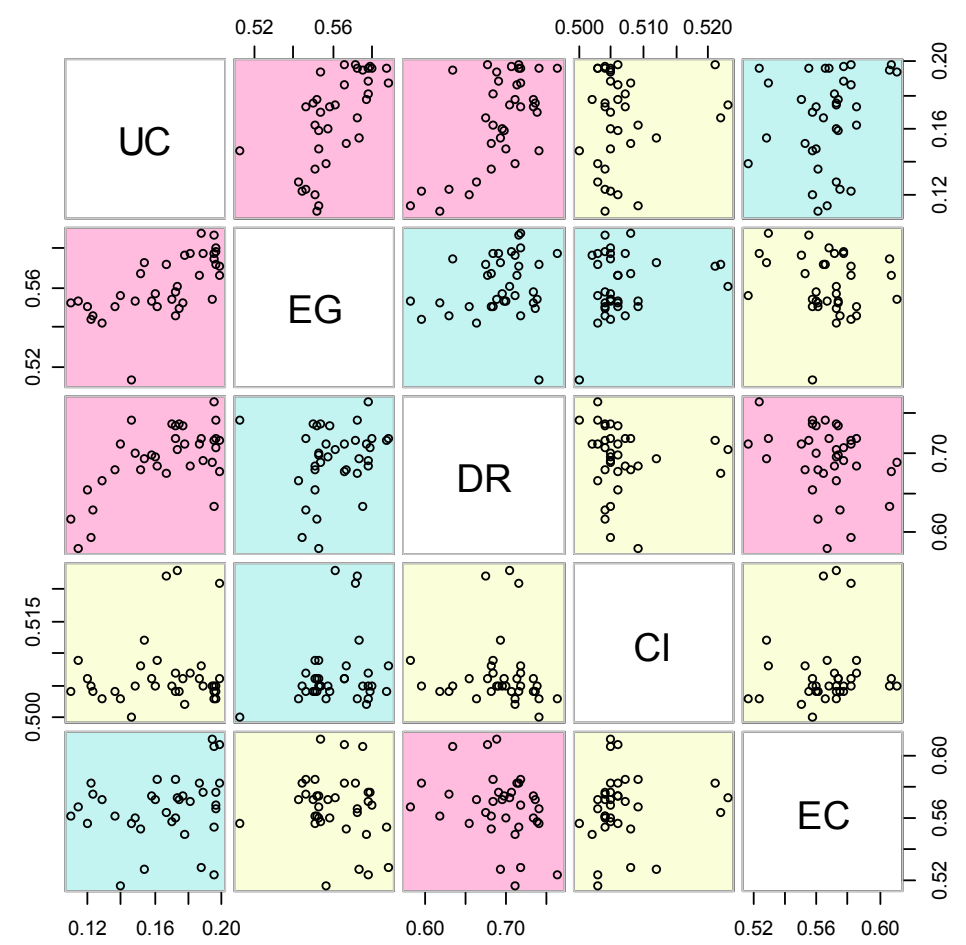

Figure 8. The scatter plot of dimensions of D-level cities.

\section{Conclusions}

Based on previous study models of urban competitiveness, this study has designed and established an evaluation system for urban competitiveness involving 12 indicators in the element layer and 58 indicators in the basic index layer. It adopted the TOPSIS method to evaluate cities' competitiveness in 28 urban clusters (including 141 Chinese cities) in 2009. Based on measurement results, four levels (A, B, C, and D) have been defined to conduct comparative analysis between cities in different regions. In addition, the relationship among different dimensions has been examined and analyzed using scatter plots and the Pearson correlation coefficient. Based on their own situations, different urban clusters and cities should improve their overall competitiveness by enhancing the competitiveness of other relevant dimensions. No doubt there are flaws in the study and further improvement is necessary. For future research, Yunnan city clusters and Taiyuan city clusters should be taken into consideration, and a comprehensive and dynamic evaluation should be performed for demonstrating long-term urban competitiveness. 


\section{Acknowledgments}

This work is supported by the National Natural Science Foundation of China No. 71103163, 71103164, 71301153, the Program for New Century Excellent Talents in University, No. NCET-13-1012, the Research Foundation of Humanities and Social Sciences of Ministry of Education of China No. 10YJC790071, the Fundamental Research Founds for National University, China University of Geosciences (Wuhan) No. CUG120111, CUG110411, G2012002A, CUG140604, China Postdoctoral Science Foundation Grant No. 20090461293, by the special grade of financial support from China Postdoctoral Science Foundation Grant No. 201003670, by the open foundation for the research center on resource environment economics in the China University of Geosciences (Wuhan) and by the open foundation for Key Laboratory of Tectonics and Petroleum Resources (China University of Geosciences), Ministry of Education No. TPR-2011-11.

\section{Author Contributions}

Haixiang Guo guided this research and proposed the integrated system solution. Xiao Liu conducted the literature review, discussed the data and drew the main conclusions. Yijing Li gathered and processed the data. Deyun Wang processed the data. Xiaohong Cheng discussed the data. All of the authors participated in the writing of the paper. The final manuscript has been approved by all authors.

\section{Appendix I}

Table A1. Index weights in each layer.

\begin{tabular}{|c|c|c|c|c|c|c|c|}
\hline \multirow[t]{2}{*}{ Subsystem layer } & \multirow[t]{2}{*}{ Element layer } & \multicolumn{2}{|c|}{ Basic index layer } & \multirow{2}{*}{ Subsystem layer } & \multirow[t]{2}{*}{ Element layer } & \multicolumn{2}{|c|}{ Basic index layer } \\
\hline & & $\mathrm{x} 1$ & 0.1606 & & & x32 & 0.2783 \\
\hline & \multirow{5}{*}{$\mathrm{ES}(0.223)$} & $\mathrm{x} 2$ & 0.1647 & \multirow{6}{*}{$\mathrm{DR}(0.15)$} & \multirow[t]{2}{*}{$\operatorname{SOP}(0.325)$} & x33 & 0.4261 \\
\hline & & $\mathrm{x} 3$ & 0.1847 & & & $\mathrm{x} 34$ & 0.2957 \\
\hline & & $\mathrm{x} 4$ & 0.1647 & & \multirow{2}{*}{$\mathrm{EP}(0.360)$} & $\mathrm{x} 35$ & 0.4848 \\
\hline & & $\times 5$ & 0.1727 & & & $\mathrm{x} 36$ & 0.5152 \\
\hline & & $\mathrm{x} 6$ & 0.1526 & & \multirow{2}{*}{$\mathrm{HP}(0.315)$} & $\mathrm{x} 37$ & 0.4000 \\
\hline & \multirow{7}{*}{ RG (0.188) } & $\times 7$ & 0.1497 & & & $\mathrm{x} 38$ & 0.6000 \\
\hline & & $\mathrm{x} 8$ & 0.1395 & \multirow{7}{*}{ CI $(0.23)$} & \multirow{3}{*}{ OOW (0.537) } & $\mathrm{x} 39$ & 0.2453 \\
\hline & & $\mathrm{x} 9$ & 0.1497 & & & $\mathrm{x} 40$ & 0.2767 \\
\hline & & $\mathrm{x} 10$ & 0.1599 & & & $\mathrm{x} 41$ & 0.2516 \\
\hline \multirow[t]{11}{*}{ EG (0.33) } & & $\mathrm{x} 11$ & 0.1224 & & \multirow{4}{*}{ FTD 0.463} & $\mathrm{x} 42$ & 0.2264 \\
\hline & & $\mathrm{x} 12$ & 0.1224 & & & $\mathrm{x} 43$ & 0.3382 \\
\hline & & $\mathrm{x} 13$ & 0.1565 & & & $\mathrm{x} 44$ & 0.3235 \\
\hline & \multirow{8}{*}{ RCL (0.198) } & $\mathrm{x} 14$ & 0.1589 & & & $\mathrm{x} 45$ & 0.3382 \\
\hline & & $\mathrm{x} 15$ & 0.1246 & \multirow{7}{*}{$\mathrm{EC}(0.29)$} & \multirow{7}{*}{ IFT (0.500) } & $\mathrm{x} 46$ & 0.1515 \\
\hline & & $\mathrm{x} 16$ & 0.1526 & & & $\mathrm{x} 47$ & 0.1515 \\
\hline & & $\mathrm{x} 17$ & 0.1340 & & & $\mathrm{x} 48$ & 0.1414 \\
\hline & & $\mathrm{x} 18$ & 0.1402 & & & $\mathrm{x} 49$ & 0.1549 \\
\hline & & $\mathrm{x} 19$ & 0.0935 & & & $\times 50$ & 0.1380 \\
\hline & & $\mathrm{x} 20$ & 0.0997 & & & $\mathrm{x} 51$ & 0.1414 \\
\hline & & $\mathrm{x} 21$ & 0.0966 & & & $\mathrm{x} 52$ & 0.1212 \\
\hline
\end{tabular}


Table A1. Cont.

\begin{tabular}{|c|c|c|c|c|c|c|c|}
\hline \multirow{2}{*}{ Subsystem layer } & \multirow[t]{2}{*}{ Element layer } & \multicolumn{2}{|c|}{ Basic index layer } & \multirow{2}{*}{ Subsystem layer } & \multirow[t]{2}{*}{ Element layer } & \multicolumn{2}{|c|}{ Basic index layer } \\
\hline & & $\mathrm{x} 22$ & 0.2806 & & & $\mathrm{x} 53$ & 0.1707 \\
\hline \multirow{9}{*}{ EG (0.33) } & \multirow{3}{*}{$\operatorname{HR}(0.178)$} & $\mathrm{x} 23$ & 0.2950 & \multirow{9}{*}{$\mathrm{EC}(0.29)$} & \multirow{9}{*}{ EI $(0.500)$} & $\mathrm{x} 54$ & 0.1672 \\
\hline & & $\mathrm{x} 24$ & 0.2158 & & & $\mathrm{x} 55$ & 0.1742 \\
\hline & & $\mathrm{x} 25$ & 0.2086 & & & $\mathrm{x} 56$ & 0.1847 \\
\hline & \multirow{6}{*}{$\mathrm{S} \& \mathrm{~T}(0.213)$} & $\mathrm{x} 26$ & 0.1435 & & & $\mathrm{x} 57$ & 0.1498 \\
\hline & & $\mathrm{x} 27$ & 0.1390 & & & \multirow{5}{*}{$\mathrm{x} 58$} & \multirow{5}{*}{0.1533} \\
\hline & & $\mathrm{x} 28$ & 0.1973 & & & & \\
\hline & & $\mathrm{x} 29$ & 0.2108 & & & & \\
\hline & & $\mathrm{x} 30$ & 0.1749 & & & & \\
\hline & & $\mathrm{x} 31$ & 0.1345 & & & & \\
\hline
\end{tabular}

Note: $\mathrm{x} 1-\mathrm{x} 58$ express indexes that correspond to the indexes of the basic index layer in Table 1.

\section{Appendix II}

Table A2. Urban clusters and cities.

\begin{tabular}{|c|c|c|}
\hline Regions & Urban clusters & Cities \\
\hline \multirow{7}{*}{ 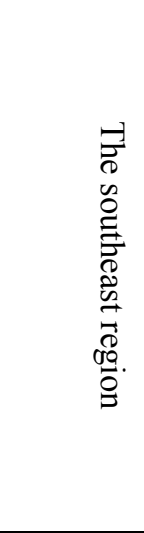 } & Yangtze River Delta & $\begin{array}{l}\text { Nanjing, Wuxi, Hangzhou, Suzhou, Huzhou, Changzhou, Zhoushan, } \\
\text { Taizhou, Shaoxing, Ningbo }\end{array}$ \\
\hline & Pearl River Delta & $\begin{array}{l}\text { Zhongshan, Shenzhen, Dongguan, Jiangmen, Guangzhou, Foshan, } \\
\text { Zhuhai, Zhoqing, Huizhou }\end{array}$ \\
\hline & Qionghai & Zhanjiang, Maoming, Yangjiang, Sanya, Haikou \\
\hline & Xuzhou & $\begin{array}{l}\text { Xuzhou, Lianyungang, Suqian, Huaibei, Suzhou, Zaozhuang, Jining, } \\
\text { Linyi }\end{array}$ \\
\hline & Shantou & Chaozhou, Shanwei, Jieyang, Shantou \\
\hline & West Strait & Ningde, Xiamen, Putian, Quanzhou, Zhangzhou \\
\hline & East Zhejiang & Taizhou, Wenzhou, Lishui \\
\hline \multirow{8}{*}{ 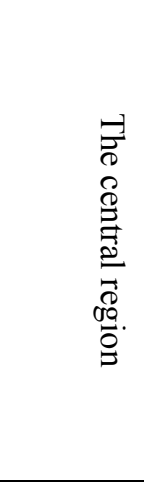 } & Hube-Henan & Suizhou, Xiangfan, Nanyang \\
\hline & Circle of the Poyang Lake & Fuzhou, Jingdezhen, Jiujiang, Nanchang, Yingtan, Shangrao \\
\hline & Anhui-Jianghuai & $\begin{array}{l}\text { Huainan, Maanshan, Liuan, Chuzhou, Bengbu, Anqing, Hefei, } \\
\text { Xuancheng, Tongling, Chizhou, Chaohu }\end{array}$ \\
\hline & Wuhan & Huangshi, Ezhou, Wuhan, Huanggang \\
\hline & Hebei-Shandong-Henan & Puyang, Handan, Liaocheng, Hebi \\
\hline & Henan-Anhui & Fuyang, Bozhou, Shangqiu, Zhoukou \\
\hline & Chang-Zhu-Tan & Changsha, Zhuzhou, Xiangtan \\
\hline & Central Plains & Pingdingshan, Xinxiang, Xucang, Luoyang, Kaifeng, Zhengzhou \\
\hline \multirow{7}{*}{ 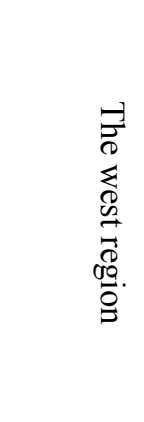 } & Yinchuan & Yinchuan, Wuzhong, Wuhai \\
\hline & Hohhot-Baotou-Ordos & Baotou, Hohhot, Ordos \\
\hline & Central Shaanxi & Xi'an, Xianyang, Baoji, Tongchuan \\
\hline & Central Guizhou & Guiyang, Zunyi, Liupanshu \\
\hline & Lanzhou & Lanzhou, Wuwei, Xining \\
\hline & Chengdu-Chongqing & $\begin{array}{l}\text { Chongqing, Chengdu, Nanchong, Mianyang, Deyang, Deyang, } \\
\text { Leshan, Suining, Guang'an }\end{array}$ \\
\hline & Nanning & Nanning, Beihai, Fangchenggang, Qinzhou \\
\hline
\end{tabular}


Table A2. Cont.

\begin{tabular}{|c|c|c|}
\hline Regions & Urban clusters & Cities \\
\hline \multirow{6}{*}{ 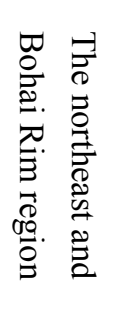 } & Shijiazhuang & Yangquan, Hengshui, Cangzhou, Langfang, Xingtai, Baoding \\
\hline & Shandong Peninsula & Rizhao, Qingdao, Dingying, Weifang, Yantai \\
\hline & Beijing-Tianjing-Tangshan & Tangshan, Tianjin, Zhangjiakou, Beijing, Qinhuangdao \\
\hline & Harbin & Tsitsihar, Daqing, Harbin, Shuangyashan \\
\hline & Changchun & Changchun, Songyuan, Siping \\
\hline & Central-southern of Liaoning & Fuxin, Shenyang, Dandong, Daqing, Anshan \\
\hline
\end{tabular}

\section{Appendix III}

Table A3. Score of urban competitiveness.

\begin{tabular}{|c|c|c|c|c|c|c|c|c|c|c|c|}
\hline City & Level & $\begin{array}{l}\text { Rank } \\
\text { of UC }\end{array}$ & $\begin{array}{c}\text { Score of } \\
\text { UC }\end{array}$ & $\begin{array}{l}\text { Rank } \\
\text { of EG }\end{array}$ & $\begin{array}{l}\text { Score } \\
\text { of EG }\end{array}$ & $\begin{array}{l}\text { Rank } \\
\text { of DR }\end{array}$ & $\begin{array}{l}\text { Score } \\
\text { of DR }\end{array}$ & $\begin{array}{l}\text { Rank } \\
\text { of CI }\end{array}$ & $\begin{array}{l}\text { Score } \\
\text { of CI }\end{array}$ & $\begin{array}{l}\text { Rank } \\
\text { of EC }\end{array}$ & $\begin{array}{l}\text { Score } \\
\text { of EC }\end{array}$ \\
\hline Suzhou & A & 1 & 0.7367 & 2 & 0.826 & 64 & 0.724 & 2 & 0.841 & 14 & 0.699 \\
\hline Guangzhou & $\mathrm{A}$ & 2 & 0.6922 & 4 & 0.762 & 101 & 0.695 & 4 & 0.652 & 1 & 0.851 \\
\hline Shenzhen & A & 3 & 0.6844 & 1 & 0.828 & 96 & 0.700 & 3 & 0.753 & 17 & 0.684 \\
\hline Beijing & A & 4 & 0.6659 & 3 & 0.795 & 131 & 0.646 & 1 & 0.869 & 24 & 0.664 \\
\hline Dongguan & A & 5 & 0.6020 & 14 & 0.670 & 9 & 0.807 & 5 & 0.648 & 2 & 0.818 \\
\hline Hangzhou & A & 6 & 0.5658 & 5 & 0.726 & 59 & 0.731 & 10 & 0.603 & 6 & 0.734 \\
\hline Nanjing & A & 7 & 0.5396 & 6 & 0.719 & 30 & 0.759 & 17 & 0.570 & 7 & 0.726 \\
\hline Wu'xi & A & 8 & 0.5137 & 7 & 0.718 & 34 & 0.756 & 13 & 0.578 & 16 & 0.691 \\
\hline Xiamen & A & 9 & 0.4982 & 12 & 0.678 & 79 & 0.714 & 35 & 0.531 & 3 & 0.769 \\
\hline Qingdao & $\mathrm{A}$ & 10 & 0.4758 & 15 & 0.668 & 44 & 0.746 & 9 & 0.611 & 13 & 0.701 \\
\hline Foshan & $\mathrm{A}$ & 11 & 0.4732 & 8 & 0.702 & 15 & 0.782 & 16 & 0.574 & 25 & 0.661 \\
\hline Tianjin & A & 12 & 0.4545 & 9 & 0.699 & 127 & 0.660 & 6 & 0.642 & 39 & 0.637 \\
\hline Ningbo & A & 13 & 0.4544 & 10 & 0.697 & 58 & 0.732 & 7 & 0.629 & 48 & 0.628 \\
\hline Zhuhai & A & 14 & 0.4539 & 30 & 0.626 & 21 & 0.773 & 24 & 0.547 & 5 & 0.759 \\
\hline Edos & A & 15 & 0.4493 & 29 & 0.630 & 23 & 0.767 & 63 & 0.511 & 4 & 0.767 \\
\hline Changzhou & $\mathrm{A}$ & 16 & 0.4226 & 16 & 0.667 & 45 & 0.746 & 28 & 0.539 & 18 & 0.680 \\
\hline Zhongshan & A & 17 & 0.4199 & 22 & 0.645 & 7 & 0.810 & 37 & 0.530 & 15 & 0.692 \\
\hline Dalian & A & 18 & 0.4108 & 17 & 0.662 & 56 & 0.733 & 20 & 0.556 & 21 & 0.670 \\
\hline Chengdu & $\mathrm{A}$ & 19 & 0.4022 & 11 & 0.686 & 129 & 0.650 & 22 & 0.552 & 28 & 0.648 \\
\hline Wuhan & A & 20 & 0.3998 & 13 & 0.677 & 139 & 0.609 & 23 & 0.548 & 22 & 0.669 \\
\hline Haikou & A & 21 & 0.3769 & 47 & 0.602 & 18 & 0.780 & 68 & 0.510 & 10 & 0.712 \\
\hline Shenyang & A & 22 & 0.3733 & 18 & 0.661 & 62 & 0.726 & 27 & 0.541 & 40 & 0.637 \\
\hline Linyi & A & 23 & 0.3674 & 46 & 0.603 & 46 & 0.744 & 54 & 0.515 & 11 & 0.710 \\
\hline Sanya & A & 24 & 0.3667 & 50 & 0.600 & 2 & 0.874 & 111 & 0.504 & 20 & 0.672 \\
\hline Xuzhou & A & 25 & 0.3664 & 51 & 0.599 & 24 & 0.765 & 50 & 0.516 & 12 & 0.707 \\
\hline Changsha & A & 26 & 0.3614 & 21 & 0.649 & 126 & 0.661 & 15 & 0.575 & 33 & 0.644 \\
\hline Shaoxing & A & 27 & 0.3576 & 19 & 0.661 & 60 & 0.731 & 29 & 0.536 & 60 & 0.619 \\
\hline Jining & A & 28 & 0.3403 & 92 & 0.573 & 68 & 0.721 & 53 & 0.516 & 9 & 0.717 \\
\hline Quanzhou & A & 29 & 0.3365 & 37 & 0.614 & 3 & 0.863 & 32 & 0.533 & 70 & 0.610 \\
\hline Zhoushan & A & 30 & 0.3353 & 41 & 0.609 & 67 & 0.721 & 8 & 0.612 & 36 & 0.638 \\
\hline Xiangfan & A & 31 & 0.3351 & 89 & 0.575 & 106 & 0.692 & 91 & 0.506 & 8 & 0.719 \\
\hline Ezhou & $\mathrm{A}$ & 32 & 0.3227 & 40 & 0.610 & 4 & 0.832 & 127 & 0.503 & 52 & 0.625 \\
\hline
\end{tabular}


Table A3. Cont.

\begin{tabular}{|c|c|c|c|c|c|c|c|c|c|c|c|}
\hline City & Level & $\begin{array}{l}\text { Rank } \\
\text { of UC }\end{array}$ & Score of UC & Rank of EG & $\begin{array}{l}\text { Score } \\
\text { of EG }\end{array}$ & $\begin{array}{l}\text { Rank } \\
\text { of DR }\end{array}$ & $\begin{array}{l}\text { Score } \\
\text { of DR }\end{array}$ & $\begin{array}{l}\text { Rank } \\
\text { of CI }\end{array}$ & $\begin{array}{l}\text { Score } \\
\text { of CI }\end{array}$ & $\begin{array}{l}\text { Rank } \\
\text { of EC }\end{array}$ & $\begin{array}{l}\text { Score } \\
\text { of EC }\end{array}$ \\
\hline Xi'an & A & 33 & 0.3207 & 20 & 0.652 & 120 & 0.677 & 39 & 0.525 & 72 & 0.610 \\
\hline Yinchuan & A & 34 & 0.3190 & 42 & 0.608 & 78 & 0.715 & 132 & 0.503 & 23 & 0.667 \\
\hline Nanchang & A & 35 & 0.3157 & 32 & 0.620 & 38 & 0.752 & 46 & 0.520 & 42 & 0.632 \\
\hline Yantai & B & 36 & 0.3156 & 35 & 0.617 & 63 & 0.725 & 19 & 0.558 & 43 & 0.631 \\
\hline Changchun & B & 37 & 0.3144 & 24 & 0.639 & 112 & 0.684 & 33 & 0.533 & 58 & 0.620 \\
\hline Hohhot & B & 38 & 0.3131 & 27 & 0.631 & 70 & 0.717 & 61 & 0.513 & 51 & 0.626 \\
\hline Baotou & B & 39 & 0.3122 & 25 & 0.637 & 89 & 0.704 & 57 & 0.515 & 56 & 0.621 \\
\hline Zhengzhou & B & 40 & 0.3080 & 26 & 0.636 & 118 & 0.678 & 38 & 0.527 & 59 & 0.620 \\
\hline Harbin & B & 41 & 0.3061 & 31 & 0.622 & 16 & 0.782 & 25 & 0.544 & 89 & 0.594 \\
\hline Huzhou & B & 42 & 0.3042 & 38 & 0.614 & 39 & 0.752 & 52 & 0.516 & 45 & 0.629 \\
\hline Huizhou & B & 43 & 0.3021 & 56 & 0.595 & 13 & 0.792 & 31 & 0.534 & 49 & 0.628 \\
\hline Suizhou & B & 44 & 0.3013 & 102 & 0.568 & 1 & 0.892 & 110 & 0.504 & 68 & 0.613 \\
\hline Wenzhou & B & 45 & 0.3007 & 28 & 0.631 & 19 & 0.775 & 49 & 0.516 & 93 & 0.585 \\
\hline Daqing & B & 46 & 0.2989 & 49 & 0.601 & 80 & 0.713 & 30 & 0.535 & 29 & 0.647 \\
\hline Chongqing & B & 47 & 0.2936 & 23 & 0.642 & 130 & 0.648 & 14 & 0.576 & 104 & 0.576 \\
\hline Dongying & B & 48 & 0.2924 & 33 & 0.618 & 5 & 0.815 & 21 & 0.553 & 132 & 0.552 \\
\hline Lianyungang & B & 49 & 0.2886 & 73 & 0.580 & 28 & 0.762 & 43 & 0.521 & 30 & 0.647 \\
\hline Jiangmen & B & 50 & 0.2861 & 52 & 0.599 & 20 & 0.775 & 45 & 0.520 & 63 & 0.617 \\
\hline Taizhou & B & 51 & 0.2838 & 36 & 0.615 & 29 & 0.761 & 51 & 0.516 & 84 & 0.599 \\
\hline Shantou & B & 52 & 0.2832 & 54 & 0.597 & 36 & 0.753 & 78 & 0.507 & 46 & 0.629 \\
\hline Hefei & B & 53 & 0.2824 & 55 & 0.597 & 108 & 0.691 & 48 & 0.520 & 31 & 0.646 \\
\hline Taizhou & B & 54 & 0.2822 & 39 & 0.614 & 66 & 0.721 & 56 & 0.515 & 65 & 0.615 \\
\hline Guiyang & B & 55 & 0.2805 & 48 & 0.602 & 93 & 0.703 & 36 & 0.531 & 44 & 0.631 \\
\hline Langfang & B & 56 & 0.2751 & 70 & 0.582 & 6 & 0.813 & 73 & 0.508 & 73 & 0.610 \\
\hline Zhangzhou & B & 57 & 0.2705 & 57 & 0.594 & 27 & 0.763 & 64 & 0.511 & 66 & 0.614 \\
\hline Weifang & B & 58 & 0.2693 & 43 & 0.607 & 84 & 0.710 & 34 & 0.532 & 71 & 0.610 \\
\hline Rizhao & B & 59 & 0.2665 & 76 & 0.579 & 132 & 0.644 & 136 & 0.503 & 26 & 0.649 \\
\hline Chaozhou & B & 60 & 0.2664 & 79 & 0.578 & 12 & 0.797 & 128 & 0.503 & 67 & 0.614 \\
\hline Xingtai & B & 61 & 0.2644 & 112 & 0.565 & 137 & 0.622 & 124 & 0.504 & 19 & 0.676 \\
\hline Jingdezhen & B & 62 & 0.2622 & 84 & 0.577 & 52 & 0.736 & 101 & 0.505 & 41 & 0.637 \\
\hline Liaocheng & B & 63 & 0.2589 & 61 & 0.588 & 47 & 0.744 & 80 & 0.507 & 61 & 0.618 \\
\hline Putian & B & 64 & 0.2569 & 71 & 0.582 & 14 & 0.791 & 59 & 0.514 & 85 & 0.598 \\
\hline Tongling & B & 65 & 0.2567 & 60 & 0.589 & 90 & 0.704 & 103 & 0.505 & 47 & 0.629 \\
\hline Deyang & B & 66 & 0.2555 & 99 & 0.571 & 61 & 0.727 & 66 & 0.511 & 37 & 0.638 \\
\hline Handan & B & 67 & 0.2546 & 80 & 0.578 & 115 & 0.680 & 85 & 0.507 & 32 & 0.645 \\
\hline Zhaoqing & B & 68 & 0.2544 & 103 & 0.568 & 10 & 0.801 & 60 & 0.513 & 75 & 0.606 \\
\hline Qinhuangdao & B & 69 & 0.2538 & 113 & 0.565 & 65 & 0.723 & 55 & 0.515 & 34 & 0.643 \\
\hline Wuzhong & B & 70 & 0.2528 & 44 & 0.607 & 11 & 0.800 & 77 & 0.507 & 136 & 0.534 \\
\hline Ma'anshan & $\mathrm{C}$ & 71 & 0.2526 & 59 & 0.590 & 40 & 0.752 & 74 & 0.508 & 77 & 0.605 \\
\hline Suqian & $\mathrm{C}$ & 72 & 0.2524 & 98 & 0.571 & 31 & 0.759 & 126 & 0.503 & 53 & 0.624 \\
\hline baoding & $\mathrm{C}$ & 73 & 0.2508 & 53 & 0.597 & 124 & 0.669 & 58 & 0.515 & 54 & 0.622 \\
\hline Hengshui & $\mathrm{C}$ & 74 & 0.2497 & 77 & 0.579 & 133 & 0.644 & 137 & 0.503 & 27 & 0.649 \\
\hline Leshan & $\mathrm{C}$ & 75 & 0.2487 & 118 & 0.557 & 94 & 0.703 & 11 & 0.602 & 57 & 0.620 \\
\hline
\end{tabular}


Table A3. Cont.

\begin{tabular}{|c|c|c|c|c|c|c|c|c|c|c|c|}
\hline City & Level & $\begin{array}{l}\text { Rank } \\
\text { of UC }\end{array}$ & Score of UC & Rank of EG & $\begin{array}{l}\text { Score } \\
\text { of EG }\end{array}$ & $\begin{array}{l}\text { Rank } \\
\text { of DR }\end{array}$ & $\begin{array}{l}\text { Score } \\
\text { of DR }\end{array}$ & $\begin{array}{l}\text { Rank } \\
\text { of CI }\end{array}$ & $\begin{array}{l}\text { Score } \\
\text { of CI }\end{array}$ & $\begin{array}{l}\text { Rank } \\
\text { of EC }\end{array}$ & $\begin{array}{l}\text { Score } \\
\text { of EC }\end{array}$ \\
\hline Xiangtan & $\mathrm{C}$ & 76 & 0.2476 & 62 & 0.588 & 105 & 0.692 & 12 & 0.602 & 92 & 0.586 \\
\hline Huaibei & $\mathrm{C}$ & 77 & 0.2475 & 104 & 0.568 & 73 & 0.717 & 82 & 0.507 & 38 & 0.638 \\
\hline Zaozhuang & $\mathrm{C}$ & 78 & 0.2467 & 63 & 0.588 & 43 & 0.747 & 65 & 0.511 & 82 & 0.602 \\
\hline Nanning & $\mathrm{C}$ & 79 & 0.2418 & 114 & 0.563 & 86 & 0.709 & 67 & 0.511 & 35 & 0.639 \\
\hline Anshan & $\mathrm{C}$ & 80 & 0.2393 & 34 & 0.618 & 85 & 0.709 & 40 & 0.523 & 133 & 0.550 \\
\hline Cangzhou & $\mathrm{C}$ & 81 & 0.2339 & 64 & 0.588 & 135 & 0.631 & 122 & 0.504 & 50 & 0.627 \\
\hline Lanzhou & $\mathrm{C}$ & 82 & 0.2283 & 45 & 0.607 & 42 & 0.748 & 79 & 0.507 & 135 & 0.535 \\
\hline Chuzhou & $\mathrm{C}$ & 83 & 0.2257 & 121 & 0.555 & 57 & 0.733 & 116 & 0.504 & 55 & 0.622 \\
\hline Maoming & $\mathrm{C}$ & 84 & 0.2254 & 115 & 0.561 & 8 & 0.809 & 112 & 0.504 & 115 & 0.571 \\
\hline Huainan & $\mathrm{C}$ & 85 & 0.2233 & 69 & 0.583 & 98 & 0.698 & 120 & 0.504 & 78 & 0.605 \\
\hline Xuchang & $\mathrm{C}$ & 86 & 0.2200 & 106 & 0.566 & 88 & 0.707 & 119 & 0.504 & 62 & 0.618 \\
\hline Chizhou & $\mathrm{C}$ & 87 & 0.2192 & 74 & 0.580 & 37 & 0.753 & 98 & 0.505 & 101 & 0.577 \\
\hline Hebi & $\mathrm{C}$ & 88 & 0.2174 & 85 & 0.577 & 35 & 0.754 & 97 & 0.505 & 100 & 0.579 \\
\hline Tangshan & $\mathrm{C}$ & 89 & 0.2170 & 87 & 0.576 & 111 & 0.687 & 26 & 0.542 & 81 & 0.602 \\
\hline Zhanjiang & $\mathrm{C}$ & 90 & 0.2149 & 122 & 0.555 & 33 & 0.757 & 96 & 0.505 & 83 & 0.601 \\
\hline Yangjiang & $\mathrm{C}$ & 91 & 0.2099 & 107 & 0.566 & 25 & 0.765 & 18 & 0.558 & 129 & 0.555 \\
\hline Zhuzhou & $\mathrm{C}$ & 92 & 0.2098 & 72 & 0.581 & 102 & 0.694 & 47 & 0.520 & 90 & 0.593 \\
\hline Beihai & $\mathrm{C}$ & 93 & 0.2086 & 88 & 0.576 & 41 & 0.749 & 130 & 0.503 & 112 & 0.572 \\
\hline Yingtan & $\mathrm{C}$ & 94 & 0.2079 & 123 & 0.554 & 50 & 0.738 & 99 & 0.505 & 80 & 0.603 \\
\hline Jieyang & $\mathrm{C}$ & 95 & 0.2074 & 93 & 0.573 & 32 & 0.757 & 86 & 0.506 & 116 & 0.569 \\
\hline Anqing & $\mathrm{C}$ & 96 & 0.2066 & 67 & 0.587 & 122 & 0.676 & 93 & 0.506 & 91 & 0.591 \\
\hline Jiujiang & $\mathrm{C}$ & 97 & 0.2057 & 90 & 0.575 & 119 & 0.678 & 71 & 0.509 & 79 & 0.603 \\
\hline Lishui & $\mathrm{C}$ & 98 & 0.2031 & 108 & 0.566 & 69 & 0.720 & 81 & 0.507 & 88 & 0.595 \\
\hline Songyuan & $\mathrm{C}$ & 99 & 0.2023 & 135 & 0.548 & 22 & 0.770 & 138 & 0.502 & 96 & 0.584 \\
\hline Xining & $\mathrm{C}$ & 100 & 0.2022 & 65 & 0.588 & 95 & 0.701 & 89 & 0.506 & 109 & 0.572 \\
\hline Mianyang & $\mathrm{C}$ & 101 & 0.2012 & 109 & 0.566 & 74 & 0.717 & 69 & 0.509 & 87 & 0.595 \\
\hline Shanwei & $\mathrm{C}$ & 102 & 0.2011 & 94 & 0.573 & 17 & 0.782 & 113 & 0.504 & 139 & 0.525 \\
\hline Huangshi & $\mathrm{C}$ & 103 & 0.2010 & 100 & 0.571 & 100 & 0.696 & 105 & 0.505 & 86 & 0.598 \\
\hline Wuhai & $\mathrm{C}$ & 104 & 0.2006 & 58 & 0.594 & 104 & 0.692 & 140 & 0.502 & 121 & 0.564 \\
\hline Suzhou & $\mathrm{C}$ & 105 & 0.1996 & 138 & 0.545 & 92 & 0.704 & 134 & 0.503 & 64 & 0.617 \\
\hline Ningde & $\mathrm{D}$ & 106 & 0.1981 & 101 & 0.571 & 77 & 0.716 & 44 & 0.521 & 97 & 0.582 \\
\hline Xinxiang & $\mathrm{D}$ & 107 & 0.1980 & 110 & 0.566 & 121 & 0.677 & 92 & 0.506 & 74 & 0.607 \\
\hline Tongchuan & $\mathrm{D}$ & 108 & 0.1964 & 78 & 0.579 & 87 & 0.707 & 118 & 0.504 & 103 & 0.577 \\
\hline Fangchenggang & $\mathrm{D}$ & 109 & 0.1963 & 96 & 0.572 & 48 & 0.741 & 131 & 0.503 & 119 & 0.566 \\
\hline Guangan & $\mathrm{D}$ & 110 & 0.1961 & 75 & 0.580 & 72 & 0.717 & 102 & 0.505 & 117 & 0.568 \\
\hline Fuxin & $\mathrm{D}$ & 111 & 0.1956 & 81 & 0.578 & 26 & 0.764 & 129 & 0.503 & 140 & 0.524 \\
\hline Shuangyashan & $\mathrm{D}$ & 112 & 0.1954 & 68 & 0.587 & 76 & 0.716 & 117 & 0.504 & 130 & 0.555 \\
\hline Huanggang & $\mathrm{D}$ & 113 & 0.1946 & 91 & 0.575 & 134 & 0.634 & 108 & 0.505 & 76 & 0.606 \\
\hline Bengbu & $\mathrm{D}$ & 114 & 0.1937 & 125 & 0.554 & 110 & 0.689 & 95 & 0.505 & 69 & 0.611 \\
\hline Pingdingshan & $\mathrm{D}$ & 115 & 0.1883 & 82 & 0.578 & 109 & 0.690 & 107 & 0.505 & 102 & 0.577 \\
\hline Baoji & $\mathrm{D}$ & 116 & 0.1870 & 66 & 0.588 & 71 & 0.717 & 75 & 0.508 & 137 & 0.529 \\
\hline Puyang & $\mathrm{D}$ & 117 & 0.1863 & 111 & 0.566 & 81 & 0.712 & 88 & 0.506 & 98 & 0.582 \\
\hline Xianyang & $\mathrm{D}$ & 118 & 0.1806 & 83 & 0.578 & 113 & 0.684 & 84 & 0.507 & 114 & 0.571 \\
\hline Siping & $\mathrm{D}$ & 119 & 0.1773 & 86 & 0.577 & 82 & 0.711 & 139 & 0.502 & 134 & 0.550 \\
\hline
\end{tabular}


Table A3. Cont.

\begin{tabular}{cccccccccccc}
\hline City & Level & $\begin{array}{c}\text { Rank } \\
\text { of UC }\end{array}$ & Score of UC & Rank of EG & $\begin{array}{c}\text { Score } \\
\text { of EG }\end{array}$ & $\begin{array}{c}\text { Rank } \\
\text { of DR }\end{array}$ & $\begin{array}{c}\text { Score } \\
\text { of DR }\end{array}$ & $\begin{array}{c}\text { Rank } \\
\text { of CI }\end{array}$ & $\begin{array}{c}\text { Score } \\
\text { of CI }\end{array}$ & $\begin{array}{c}\text { Rank } \\
\text { of EC }\end{array}$ & $\begin{array}{c}\text { Score } \\
\text { of EC }\end{array}$ \\
\hline Zunyi & D & 120 & 0.1770 & 129 & 0.552 & 55 & 0.734 & 87 & 0.506 & 106 & 0.574 \\
Xuancheng & $\mathrm{D}$ & 121 & 0.1746 & 134 & 0.550 & 53 & 0.735 & 114 & 0.504 & 111 & 0.572 \\
Suining & $\mathrm{D}$ & 122 & 0.1735 & 116 & 0.561 & 91 & 0.704 & 41 & 0.523 & 108 & 0.573 \\
Tsitsihar & $\mathrm{D}$ & 123 & 0.1726 & 136 & 0.546 & 75 & 0.717 & 83 & 0.507 & 95 & 0.585 \\
Fuzhou & $\mathrm{D}$ & 124 & 0.1725 & 117 & 0.558 & 54 & 0.734 & 115 & 0.504 & 125 & 0.560 \\
Qinzhou & $\mathrm{D}$ & 125 & 0.1697 & 124 & 0.554 & 51 & 0.737 & 100 & 0.505 & 126 & 0.558 \\
Luoyang & $\mathrm{D}$ & 126 & 0.1669 & 97 & 0.572 & 123 & 0.675 & 42 & 0.522 & 120 & 0.564 \\
Kaifeng & $\mathrm{D}$ & 127 & 0.1616 & 131 & 0.551 & 114 & 0.683 & 70 & 0.509 & 94 & 0.585 \\
Zhangjiakou & $\mathrm{D}$ & 128 & 0.1601 & 119 & 0.557 & 103 & 0.694 & 106 & 0.505 & 110 & 0.572 \\
Nanchong & $\mathrm{D}$ & 129 & 0.1584 & 126 & 0.553 & 99 & 0.697 & 90 & 0.506 & 107 & 0.574 \\
Dandong & $\mathrm{D}$ & 130 & 0.1539 & 95 & 0.573 & 107 & 0.692 & 62 & 0.512 & 138 & 0.528 \\
Shangrao & $\mathrm{D}$ & 131 & 0.1512 & 105 & 0.567 & 116 & 0.680 & 76 & 0.508 & 131 & 0.553 \\
Chaohu & $\mathrm{D}$ & 132 & 0.1483 & 127 & 0.553 & 97 & 0.699 & 104 & 0.505 & 124 & 0.560 \\
Wuwei & $\mathrm{D}$ & 133 & 0.1467 & 141 & 0.513 & 49 & 0.741 & 141 & 0.500 & 128 & 0.557 \\
Liupanshui & $\mathrm{D}$ & 134 & 0.1392 & 120 & 0.556 & 83 & 0.711 & 133 & 0.503 & 141 & 0.517 \\
Liu'an & $\mathrm{D}$ & 135 & 0.1362 & 132 & 0.551 & 117 & 0.680 & 121 & 0.504 & 122 & 0.561 \\
Bozhou & $\mathrm{D}$ & 136 & 0.1287 & 140 & 0.542 & 125 & 0.664 & 135 & 0.503 & 113 & 0.572 \\
Shangqiu & $\mathrm{D}$ & 137 & 0.1237 & 137 & 0.546 & 136 & 0.628 & 123 & 0.504 & 105 & 0.575 \\
Zhoukou & $\mathrm{D}$ & 138 & 0.1226 & 139 & 0.544 & 140 & 0.595 & 109 & 0.505 & 99 & 0.582 \\
Nanyang & $\mathrm{D}$ & 139 & 0.1201 & 133 & 0.551 & 128 & 0.653 & 94 & 0.506 & 127 & 0.557 \\
Yangquan & $\mathrm{D}$ & 140 & 0.1142 & 128 & 0.553 & 141 & 0.580 & 72 & 0.509 & 118 & 0.567 \\
Fuyang & $\mathrm{D}$ & 141 & 0.1103 & 130 & 0.552 & 138 & 0.617 & 125 & 0.504 & 123 & 0.561 \\
\hline & & & & & & & & & & &
\end{tabular}

\section{Conflicts of Interest}

The authors declare no conflict of interest.

\section{References}

1. Allen, J.S. Global City-Regions: Trends, Theory, Policy; Oxford University Press: Oxford, UK, 2001.

2. Fang, C.L.; Yao, S.M.; Liu, S.H. China's Urban Agglomeration Development Report 2010; Science Press: Beijing, China, 2010.

3. Liu, H. Comprehensive carrying capacity of the urban agglomeration in the Yangtze River Delta, China. Habitat Int. 2012, 36, 462-470.

4. Sun, Y. The Analysis of urban competitiveness of the Three Largest Urban Clusters in China. Econ. Soc. Dev. 2006, 12, 43-52.

5. Xu, X.Q.; Cheng, Y.H. Spatial-temporal Changes of Urban Competitiveness in Urban Cluster of Pearl River Delta. Sci. Geogr. Sinica 2006, 3, 257-265.

6. Guo, H.X.; Chen, L. Comparative Analysis on Urban Competitiveness Based on TOPSIS Method-A Case Study of Pearl River Delta City Group. East China Econ. Manag. 2013, 1, 69-74. 
7. Shi, Y.S.; Zhang, H.Y. An Analysis of Urban Comprehensive Competitiveness and Regional Advantages of the Yangtze River Delta. Urban Plan. Forum 2002, 1, 17-21.

8. Yu, L.Y.; Guo, H.J. The Evaluation Index System Research of Urban Competitiveness of Yangtze River Delta under City Cooperation framework. Sci. Technol. Manag. Res. 2010, 11, 95-98.

9. Porter, M.E. The Competitive Advantage of Nation; The Free Press: New York, NY, USA, 1990; pp. 13-20.

10. Gordon, L.R.; Cheshire, P.C. Location Advantage and the Lessons of Territorial Competition in Europe; Springer-Berlin-Heidelberg: Berlin, Germany, 1998.

11. Webster, D. Urban Competitiveness Assessment in Developing Country Urban Regions: The Road Forward; Paper Prepared for Urban Group; The World Bank: Washington, DC, USA, 2000.

12. Iain, B. Cities and competitiveness. Urban Stud. 1999, 36, 795-809.

13. Ning, Y.M.; Tang, L.Z. The Concept and Indicator System of Urban Competitive Capacity. Urban Res. 2001, 3, 19-22.

14. Schwab, K.; Porter M. The Global Competitiveness Report 2008-2009; World Economic Forum: Geneva, Switzerland, 2006.

15. Hutton, T.A. Trajectories of the new economy: Regeneration and dislocation in the inner city. Urban Stud. 2009, 46, 987-1001.

16. Kresl, P.K.; Singh, B. Competitiveness and the urban economy: Twenty-four large US metropolitan areas. Urban Stud. 1999, 36, 1017-1028.

17. Tong, Q. Northwest Area Center Urban Competitiveness Comparative Study from 1990; Xi'an University of Architecture \&Technology: Xi'an, China, 2004.

18. Jiang, Y.; Shen, J. Measuring the urban competitiveness of Chinese cities in 2000. Cities 2010, 27, 307-314.

19. Singhal, S.; McGreal, S.; Berry, J. An evaluative model for city competitiveness: Application to UK cities. Land Use Policy 2013, 30, 214-222.

20. Porter, M.E.; Sachs, J.; Schwab, K. Global Competitiveness Report; Oxford University Press: Oxford, UK, 2002; pp. 16-25.

21. Lopez-Claros, A.; Schwab, K.; Michael, E. The Global Competitiveness Report 2006-2007; World Economic Forum: Geneva, Switzerland, 2006.

22. Ni, P.; Kresl, P.K. Global Urban Competitiveness Report 2007-2008; Social Sciences Academic Press: Beijing, China, 2009.

23. Porter, M.E. The Competitive Advantage of Nations; Huaxia Press: Beijing, China, 2002.

24. Rondinelli, D.A.; Vastag, G. Urban Economic Growth in the 21st Century: Assessing the International Competitiveness of Metropolitan Areas. In Migration, Urbanization and Development: New Directions and Issues; United Nations Population Fund and Kluwer Academic Publishers: New York, NY, USA, 1998.

25. Ni, P. Annual Report on Urban Competitiveness; Social Science Academic Press: Beijing, China, 2008.

26. Lin, B.; Feng, Y. A Survey of Urban Competitiveness Theory. Econ. Perspect. 2003, 1, 56-59.

27. Chinese Academy of Social Sciences. Blue Book of Urban Competitiveness in 2007; Social Sciences Academic Press: Beijing, China, 2007.

28. China City Statistical Yearbook; Chinese Statistical Bureau Press: Beijing, China, 2010. 
29. China Statistical Yearbook on Environment; Chinese Statistical Bureau Press: Beijing, China, 2010.

30. China Energy Statistical Yearbook; Chinese Statistical Bureau Press: Beijing, China, 2010.

31. Hwang, C.L.; Yoon, K. Multiple Attribute Decision Making: Methods and Applications; Springer: Berlin, Germany, 1981.

(C) 2015 by the authors; licensee MDPI, Basel, Switzerland. This article is an open access article distributed under the terms and conditions of the Creative Commons Attribution license (http://creativecommons.org/licenses/by/4.0/). 